Document downloaded from:

http://hdl.handle.net/10251/47360

This paper must be cited as:

Payri Marín, R.; Salvador Rubio, FJ.; Gimeno García, J.; Morena Borja, JDL. (2011).

Influence of injector technology on injection and combustion development, Part 1: Hydraulic characterization. Applied Energy. 88(4):1068-1074. doi:10.1016/j.apenergy.2010.10.012.

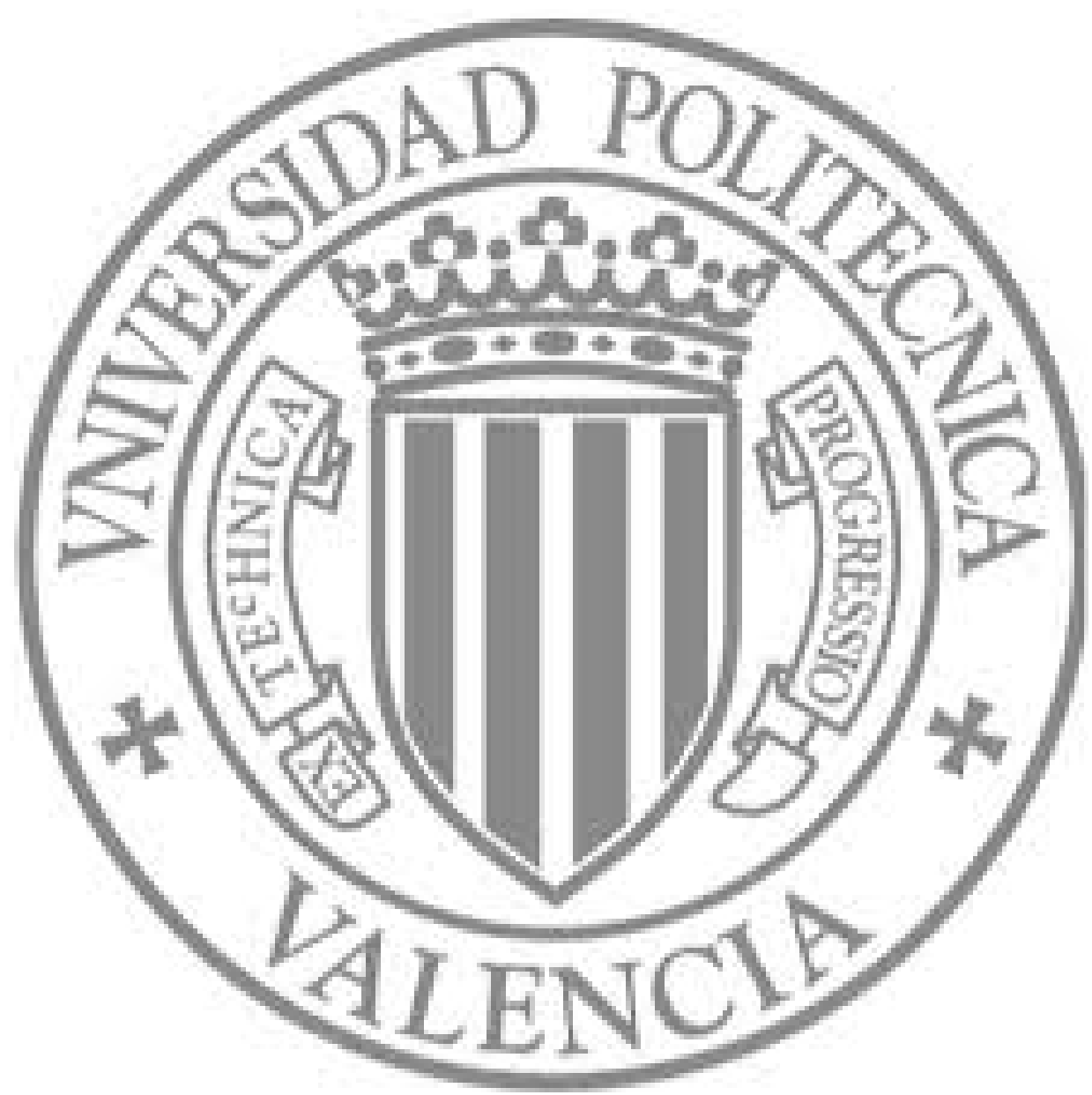

The final publication is available at

http://dx.doi.org/10.1016/j.apenergy.2010.10.012

Copyright Elsevier 


\section{INFLUENCE OF INJECTOR TECHNOLOGY ON INJECTION AND COMBUSTION DEVELOPMENT- PART 1: HYDRAULIC CHARACTERIZATION}

R. Payri, F. J. Salvador (*), J. Gimeno, J. De la Morena

CMT-Motores Térmicos, Universidad Politécnica de Valencia

Camino de Vera s/n, E-46022 Spain.

(*) Corresponding author:

Dr. F. Javier Salvador, fsalvado@mot.upv.es

CMT-Motores Térmicos, Universidad Politécnica de Valencia

Camino de Vera s/n, E-46022 Spain.

Telephone: +34-963879659

FAX: +34-963877659 


\section{ABSTRACT}

An experimental study of two real multi-hole Diesel injectors is performed under current DI Diesel engine operating conditions. The aim of the investigation is to study the influence of injector technology on the flow at the nozzle exit and to analyse its effect on the spray in evaporative conditions and combustion development. The injectors used are two of the most common technologies used nowadays: solenoid and piezoelectric. The nozzle for both injectors is very similar since the objective of the work is the understanding of the influence of the injector technology on spray characteristics for a given nozzle geometry. In the first part of the study, experimental measurements of hydraulic characterization have been analyzed for both systems. Analysis of spray behavior in evaporative conditions and combustion development will be carried out in the second part of the work. Important differences between both injectors have been observed, especially in their transient opening and closing of the needle, leading to a more efficient air-fuel mixing and combustion processes for the piezoelectric actuated injector.

\section{KEY WORDS:}

Diesel spray, injector technology, momentum flux.

\section{NOMENCLATURE}
$A_{e f}$
Effective area.
$A_{o} \quad$ Geometric outlet area
$C_{a} \quad$ Area coefficient
$C_{d} \quad$ Discharge coefficient
$C_{v} \quad$ Velocity coefficient
$D_{e f} \quad$ Effective diameter 
$D_{i} \quad$ Inlet diameter of a nozzle orifice.

$D_{o} \quad$ Outlet diameter of a nozzle orifice.

ET Energizing time

$k$-factor Nozzle conicity.

$M_{f} \quad$ Momentum flux at the nozzle outlet orifice.

$m_{f} \quad$ Fuel mass flow rate.

$P_{\text {back }} \quad$ Backpressure.

$P_{i n j} \quad$ Injection pressure.

$R_{a} \quad$ Upper rounding radii

$R_{b} \quad$ Lower rounding radii

SOI Start of Injection

$u_{e f} \quad$ Effective velocity at the outlet orifice.

$u_{\text {berno }} \quad$ Theoretical velocity at the outlet orifice.

\section{GREEK SYMBOLS:}

$\Delta P$

$\rho_{f}$
Pressure drop, $\Delta P=P_{\text {inj }}-P_{\text {back. }}$

Fuel density. 


\section{INTRODUCTION}

The injector of a Diesel engine is one of the most important elements in nowadays Diesel engine design. The injection system is the responsible of air-fuel mixing process and, as a consequence, it has a strong effect on combustion development, engine performance and pollutant formation. For this reason, injector and nozzle design have been improved in the last years in order to fulfil new stringent emission regulations while improving or, at least, maintaining the efficiency of the engine.

Injection system development has been analyzed from different points of view over the last years. Several authors have studied internal nozzle flow conditions using experimental ([1-3]) and computational tools ([3-6]), as a way to get further knowledge about injection system performance. The link between flow characteristics at the nozzle exit and spray behaviour has been also examined, both in evaporative ([7-10]) and non-evaporative conditions ([11-15]). Additionally, optical techniques have been extensively used to analyze combustion development in real engine conditions ([16-20]). Thus, characteristics of injection and combustion process under operative conditions can be widely analyzed for a given injector and nozzle.

The aim of this research is to understand the influence of injector technology on internal nozzle flow characteristics and fuel-air mixing in evaporative conditions, as well as its consequences on combustion development. For this purpose, in this research article, two injectors with similar nozzle flow capacity have been characterized geometrically and hydraulically. The mass flow rate and the momentum flux have been measured for a wide range of typical engine injection and in-cylinder pressures. The injection rate measurements have served, on the one hand, to detect the presence of cavitation in the nozzle ([2,6]), as well as to evaluate the discharge coefficient. On the other hand, in combination with measurements 
of momentum flux, mass flow rate measurements have allowed to determine the velocity at the nozzle exit $([2,21])$.

In the second part of this work included in the accompanied paper [22], measurements of liquid spray penetration in evaporative conditions have been performed, and visualization techniques will be applied for the characterization of diffusive flame (related with soot oxidation) and $\mathrm{CH}-$ and $\mathrm{OH}-$ radicals.

This paper is divided in 4 sections. First of all, a wide description of experimental facilities is made, including the injectors' description and fuel properties, together with a detailed summary of the test matrix. After this, experimental results obtained from hydraulic characterization are described, analyzing both the transient response of the system and their development at quasi-steady conditions. Finally, conclusions about the main differences between both systems pointed out.

\section{EXPERIMENTAL TOOLS AND CONDITIONS}

A customized common rail injection system was used in the experiments [23]. The system is constituted by a high pressure pump, able to reach up to $200 \mathrm{MPa}$, and a conventional rail with a pressure regulator. A Repsol CEC RF-06-99, with a density of $843 \mathrm{~kg} / \mathrm{m}^{3}$ and a kinematic viscosity of $2.847 \mathrm{~mm}^{2} / \mathrm{s}$ (measured at $40^{\circ} \mathrm{C}$ ), was used as fuel in the experiments. The summary of some physical and chemical properties is shown in Table 1.

Two Bosch injectors with different technologies have been used: a solenoid injector (second generation) and a piezoelectric injector (third generation). Even though each injector was mounted with a different 8-hole microsac tapered nozzle, Bosch flow number was similar for both nozzles. This parameter is defined as the flow rate injected in 30 seconds using an injection pressure and a backpressure of $10 \mathrm{MPa}$ and $0.1 \mathrm{MPa}$ respectively. 


\subsection{Internal geometry determination}

The nozzle geometry has an important influence on injection process and combustion development [24-26]. For this reason, the silicone methodology [27] has been employed to get information about the internal geometry of the nozzles used for this study. This technique consists on the application of a special silicone in order to obtain a mould of the nozzle. Once the moulds are prepared, pictures are obtained using a Scanning Electron Microscope (SEM). These images are processed using CAD software in order to evaluate nozzle geometric parameter such as inlet and outlet diameter or upper and lower rounding radii, as seen in Figure 1 for the nozzle mounted on the piezoelectric injector.

The degree of conicity can also be evaluated for each nozzle and each hole by the k-factor, defined as:

$k-$ factor $=\frac{D_{i}-D_{o}}{10}$

A summary of the results obtained from this technique are shown in Table 2. As it can be seen, although the two nozzles were defined with the same Bosch flow number, there are significant differences between them. In particular, the piezoelectric system's nozzle shows a lower outlet diameter and higher degree of conicity than the solenoid one.

\subsection{Injection rate meter and spray momentum test rig}

The injection rate measurements were carried out in a standard injection rate discharge curve indicator based in the Bosch method (anechoic tub), described in [28]. In order to obtain a good estimation of the experimental errors, several repetitive measurements were carried out at the same test point (energizing time, rail pressure, and backpressure). Dispersion around 0.6 $\%$ was obtained with proper calibration of the equipment.

The spray momentum is based in the measurement of the impingement force of a spray on a surface. This force is equivalent to the spray momentum flux, and can be determined with the 
use of the spray momentum test rig as presented in [2]. Sprays are injected into a chamber that can be pressurized with nitrogen up to $8 \mathrm{MPa}$ in order to simulate pressure discharge conditions that are representative of real pressure conditions inside the engine combustion chamber during the injection process.

The spray momentum measuring principle is shown in Figure 2. The impact force is measured with a piezoelectric pressure sensor calibrated in order to measure force and placed at $5 \mathrm{~mm}$ from the nozzle hole exit. The sensor frontal area and position are selected so that spray impingement area is much smaller than that of the sensor. The pressure inside the chamber is constant and surrounds the entire spray, and fuel deflected is perpendicular to the axis direction. Under this assumption, and due to the conservation of momentum, the force measured by the sensor is the same as the axial momentum flux at the hole outlet or at any other axial location [6].

\subsection{Test matrix.}

The hydraulic characterization of the injectors is based on the mass flow rate and momentum measurements. They were carried out for different representative engine values of injection pressures (30, 50, 80, 120, 160 and $200 \mathrm{MPa}$ ) and back pressures (2, 5, 8, 12 and $17 \mathrm{MPa}$ ). The injector characterization was made both in transient operation (opening and closing phases) and under quasi-steady conditions at full needle lift. For the transient characterization, the energizing times (ET) are searched in order to have injections of 1 and $3 \mathrm{mg} / \mathrm{shot}$. Quasisteady conditions are obtained at longer energizing times. Nevertheless, the time needed to reach the stabilized mass flow values is different for each injection pressure. In particular, 1.5 ms for the highest injection pressures (160 and $200 \mathrm{MPa}), 2 \mathrm{~ms}$ for an injection pressure of $120 \mathrm{MPa}$, and $3 \mathrm{~ms}$ for the rest of the values (30, 50 and $80 \mathrm{MPa}$ ) are chosen for this analysis. 


\section{HYDRAULIC CHARACTERIZATION RESULTS}

The behavior of the injection system has been analyzed from two points of view. First, transient development has been characterized by the use of pilot injections, at which both mass flow rate and momentum flux are controlled by the needle dynamics during the whole injection event. Afterwards, characterization of mass flow rate and momentum flux will be made at stationary conditions, using long injection pulses.

\subsection{Injection rate and spray momentum during opening and closing phases}

Development of the injection systems at short pulses is analyzed in order to study injector behaviour at transient conditions. Due to the different conception and dynamic response between the solenoid valve and the piezoelectric actuator, strong deviation is expected between the two systems.

In Figures 3 and 4, results on injection rate for two pressures are presented at low energizing time conditions, together with the electric command signals (in terms of intensity for the solenoid system and voltage for the piezoelectric), as well as the instantaneous pressure inside the rail. These results are obtained for short injection pulses, corresponding to 1 and 3 milligrams injected per shot. When comparing the transient behaviour of mass flow rate, it can be immediately seen that piezoelectric injector shows a much lower hydraulic delay (i.e., the injector opens at a shorter time from the signal reception). Besides this, the opening slopes of the signals are considerably different, showing that needle dynamics are faster for the piezoelectric injector, as it was expected $([4,29])$. This fact is more appreciable at low injection pressures. Due to their better dynamic response, piezoelectric injectors are more adequate to develop multiple injection strategies, because they are capable of operating with repeatable close injections of small and precise fuel amounts.

In Figure 5 an example for spray momentum is presented for an injection pressure of $80 \mathrm{MPa}$ and a chamber pressure of $5 \mathrm{MPa}$. Again, much shorter hydraulic delay between the start of 
energizing and the start of injection is seen for the piezoelectric system. With respect to the opening and closing slope, piezoelectric system shows again a faster behaviour, although the difference is not as significant as seen for mass flow rate curves.

\subsection{Mass flow rate and momentum flux results in maximum lift conditions}

The injector characterization in terms of mass flow rate and momentum results was also made under quasi-steady conditions at full needle lift in order to isolate the influence of nozzle geometry on the internal flow from others effects due to needle opening and closing. To obtain these conditions, large injection pulses were applied, thus enabling the elimination of the opening and closing effects. Typical top hat profiles can be observed for both variables at maximum needle lift [2]. It is during this period that averaging has been carried out. Injection rate curves for the different injection pressure levels at a discharge pressure of 5 MPa are represented in Figure 6. Apart from the differences already described in the opening and closing phases, which make that mass flow rate curves seem more squared for the piezoelectric system, it can be seen that maximum value is significantly higher for the solenoid injector. Nevertheless, it must be taken into account that, despite the two nozzles used have the same flow capacity definition in terms of Bosch flow number, diameter of the nozzle mounted in the solenoid injector is slightly higher, which is the main reason of its higher values of stationary mass flow. Additionally it can be observed that, despite the same energizing time has been selected for the two systems, piezoelectric injector remains opened for a longer interval. This is one of the reasons, apart from the faster opening and closing of the needle, why piezoelectric system requires shorter energizing times in order to inject the same amount of fuel as solenoid injector. Similar conclusions can be stated from Figure 7, where injection rate curves are represented for different chamber pressures at an injection pressure of $160 \mathrm{MPa}$. 
The discharge coefficient at maximum needle lift is depicted against the pressure drop for both injectors in Figure 8. In this figure, there is a group of points for each injection pressure. Inside each group, there is one point for each backpressure tested (2, 5, 8, 12 and $17 \mathrm{MPa})$. As it can be seen, despite having a lower mass flow at stabilized conditions, piezoelectric system shows higher values of discharge coefficient than solenoid one. Nevertheless, it is known that this parameter is mainly dependent on nozzle geometry. In particular, the differences in terms of $C_{d}$ seen in figure 8 could be explained because of the higher degree of conicity of the nozzle mounted on the piezoelectric system [30, 31]. Additionally, it is appreciable that discharge coefficient suffers a significant decrement at several points for the injection pressures of 120, 160 and $200 \mathrm{MPa}$. This is due to cavitation phenomenon, which appears in the studied nozzles for the most critical conditions. From experimental results, it can be seen that cavitation is more severe for the solenoid system, which can be explained due to the higher diameter and lower degree of conicity of its nozzle [6].

In Figure 9, the momentum flux results for a long energizing time are plotted for both injectors at a chamber pressure of $5 \mathrm{MPa}$. In this graph, momentum flux curves are represented against time from Start of Injection (SOI), so that influence of injection system on hydraulic delay is not appreciable. As it was stated from mass flow rate analysis (figure 6), piezoelectric injector closes later than the solenoid one. Furthermore, maximum value of momentum flux is higher for the solenoid system, although the difference is not as significant as seen from mass flow rate curves.

The combination of results of injection rate and spray momentum provides the determination of outlet velocity and outlet effective area (or effective diameter) just combining both results and applying the following formulas:

$$
u_{e f}=\frac{\dot{M}_{f}}{\dot{m}_{f}}
$$




$$
A_{e f}=\frac{\dot{m}_{f}^{2}}{\rho_{f} \cdot \dot{M}_{f}}
$$

where $\rho_{f}$ is the liquid fuel density.

In Figures 10 and 11 effective velocity and effective diameter calculated using mass and momentum flux values at stabilized conditions are depicted. As it can be seen in figure 10, outlet velocity is mainly dependent on injection conditions, and the difference between the two systems is not appreciable. In order to isolate the effect of injector technology from pressure drop, velocity coefficient $\left(C_{v}\right)$ is calculated as the ratio between $u_{e f}$ and theoretical velocity obtained from Bernoulli equation ( $u_{\text {berno }}$ ). This information is shown in Figure 12, where it can be seen that, in general terms, piezoelectric system has higher values for velocity coefficient than the solenoid injector. With respect to effective diameter $\left(D_{e f}\right)$ results, plotted in figure 11, the differences are scaled in the same way as the real geometry of the two nozzles obtained from silicon methodology [27]. The decrease observed for a given injection pressure as chamber pressure decreases is due to cavitation phenomena [2].

\subsection{Transient velocity determination}

In the previous section, effective velocity has been evaluated as the ratio between momentum flux and mass flow rate at stationary conditions (maximum needle lift). Following a similar reasoning, instantaneous outlet velocity at non-stabilized conditions, where the needle dynamics are influencing the flow inside the nozzle, can be evaluated.

For this purpose, information from mass flow rate and momentum flux measurements obtained for low injection pulses is combined. Examples of the results obtained from this analysis are depicted in Figure 13 for low injection pressure and Figure 14 for high injection pressure. Paying attention to figure 13 (low injection pressure conditions), it can be observed that piezoelectric system show a considerably higher transient velocity; this will imply a faster, and so, more efficient mixing for this system with respect to the solenoid injector. 
Meanwhile, as injection pressure gets higher, the differences in the dynamic behaviour between both technologies are reduced, as it occurred with the instantaneous mass flow rate signals. Nevertheless, it can be noted that velocity value is still higher for the piezoelectric system for analogous conditions.

\section{CONCLUSIONS}

The aim of this paper has been to study the influence of injector technology on internal flow. For this purpose, in the paper, two injectors with a similar nozzle have been characterized geometrically and hydraulically. The main conclusion that can be established from these experiments it is that piezoelectric injector has a better dynamic response and a higher transient injection velocity. These differences are more severe in low injection pressure conditions. At injection pressures higher than $120 \mathrm{MPa}$, the transient development of the two systems becomes more similar, although piezoelectric system maintains higher injection velocities.

Analysis of injection process at maximum needle lift shows that discharge coefficient is higher for the piezoelectric system at all the conditions studied, as well as cavitation phenomenon is more likely to occur for the solenoid injector. Nevertheless, this fact can be explained in terms of nozzle geometry, as the nozzle mounted in the piezoelectric injector has shown to have a lower outlet velocity and higher degree of conicity. With respect to velocity at these stabilized conditions, the differences observed are less significant than those obtained from the transient study, although values obtained for piezoelectric system are higher again.

\section{ACKNOWLEDGEMENTS}

This research has been funded in the frame of the Project "Caracterización experimental de la cavitación en el flujo interno e influencia sobre modelos de chorro Diesel”, Reference TRA2007-68006-C02-01, from Spanish government. 


\section{REFERENCES}

[1] Kent JC, Brown GM. Nozzle exit flow characteristics for square-edged and rounded inlet geometries, Combust Sci Technol 1983; 30: 121-132.

[2] Payri R, García JM, Salvador FJ, Gimeno, J. Using spray momentum flux measurements to understand the influence of Diesel nozzle geometry on spray characteristics, Fuel 2005; 84: 551-561.

[3] Kegl B, Kegl M, Pehan S, Optimization of an injection system for Diesel and biodiesel usage. Energ Fuels 2008; 22: 1046-1054.

[4] Chung N-H, Oh B-G, Sunwoo M-H, Modelling and injection rate estimation of common-rail injectors for direct-injection diesel engines. P. I. Mech. Eng. D-J. Aut. 2008; 222: 1089-1101.

[5] Schmidt DP, Corradini ML, The internal flow of Diesel fuel injector nozzles: a review, Int J Engine Research 2001; 2: 1-22.

[6] Macián V, Payri R, Margot X, Salvador FJ, A CFD analysis of the influence of Diesel nozzle geometry on the inception of cavitation, Atomization Sprays 2003; 13: 579-604.

[7] Naber JD, Siebers DL, Effect of gas density and vaporization on penetration and dispersion of diesel sprays, SAE Paper 960034; 1996.

[8] Siebers DL, Scaling liquid-phase fuel penetration in diesel sprays based on mixinglimited vaporization, Transaction of the SAE 1999; 108 (3): 703-728.

[9] Desantes JM, Pastor JV, Payri R, Pastor JM, Experimental characterization of internal nozzle flow and diesel spray behaviour. Part II. Evaporative conditions, Atomization Sprays 2005; 15: 517-543.

[10] Payri R, Salvador FJ, Gimeno J, Zapata LD, Diesel nozzle geometry influence on spray liquid-phase fuel penetration in evaporative conditions. Fuel 2008; 87: 1165-1176.

[11] Hiroyasu H, Arai M, Structures of fuel sprays in Diesel engines, SAE Paper 900475; 1990.

[12] Payri F, Bermúdez V, Payri R, Salvador FJ, The influence of cavitation on the internal flow and the spray characteristics in Diesel injection nozzles. Fuel 2004; 83: 419-31.

[13] Soteriou C, Andrews RJ, Smith M, Direct injection Diesel sprays and the effect of cavitation and hydraulic flip on atomisation, SAE Paper 950080; 1995.

[14] Roisman IV, Araneo L, Tropea C, Effect of ambient pressure on penetration of a diesel spray, Int J Multiphas Flow 2007; 33 (8): 904-920.

[15] Goney KH, Corradini ML, Isolated effects of ambient pressure, nozzle cavitation and hole inlet geometry on Diesel injection spray characteristics, SAE Paper 2000-01-2043; 2000.

[16] Gaydon A. The spectroscopy of flames. 2nd edition; FRS Chapman \& Hall: London; 1974. 
[17] Dec JE, Espey C, Chemiluminescence imaging of auto-ignition in a DI Diesel engine. SAE paper 982685; 1998.

[18] Costa M, Vaglieco BM, Corcione FE, Radical species in the cool-flame regime of diesel combustion: a comparative numerical and experimental study. Exp Fluids 2005; 39: 512-524.

[19] Payri R, Salvador FJ, Gimeno J, De la Morena J. Effects of nozzle geometry on direct injection diesel engine combustion process. Appl Therm Engi 2009; 29 (10): 2051-2060.

[20] Pickett LM, Kook S, Persson H, Andersson Ö, Diesel fuel jet lift-off stabilization in the presence of laser-induced plasma ignition. P Combust Inst 2009; 32: 2793-2800.

[21] Desantes JM, Payri R, Salvador FJ, Gil A, Development and validation of a theoretical model for Diesel spray penetration, Fuel 2006; 85: 910-917.

[22] Payri R, Salvador FJ, Gimeno J, De la Morena J, Influence of injector Technology on injection and combustion development. Part 2. Combustion analysis. Submitted to Appl Energy; 2010.

[23] Flaig U, Polach W, Zieglet G, Common rail system (CR-System) for passenger car DI Diesel engines; Experiences with applications for series productions projects, SAE Paper 1999-01-0191; 1999.

[24] Kampmann S, Dittus B, Mattes P, Kirner M, The influence of hydro grinding at VCO nozzles on the mixture preparation in a DI Diesel engine, SAE Paper 960867; 1996.

[25] Ganippa LC, Andersson S, Chomiak J, Combustion characteristics of Diesel sprays from equivalent nozzles with sharp and rounded inlet geometries, Combust. Sci. Technol. 2003; 175: 1015-1032.

[26] Park SW, Reitz RD, Modelling the effect of injector nozzle-hole layout on diesel engine fuel consumption and emissions. J. Eng. Gas Turb. Power 2008; 30 (3): 032805.

[27] Macián V, Bermúdez V, Payri R, Gimeno J, New technique for determination of internal geometry of a Diesel nozzles with the use of silicone methodology, Exp Techniques 2003; 27: 39-43.

[28] Payri R, Salvador FJ, Gimeno J, Bracho G, A new methodology for correcting the signal cumulative phenomenon on injection rate measurements. Exp Techniques 2008; 31-1: 46-49.

[29] Suh HK, Park SW, Lee CS, Effect of piezo-driven injection system on the macroscopic and microscopic atomization characteristics of diesel fuel spray. Fuel 2007; 86: 2833-2845.

[30] Lichtarowicz AK, Duggins RK, Markland E, Discharge coefficients for incompressible non-cavitating flow through long orifices, J. Mech. Eng. Sci 1965; 7 (2): 210219. 
[31] Payri R, Salvador FJ, Gimeno J, De la Morena J, Study of cavitation phenomena based on a technique for visualizing bubbles in a liquid pressurized chamber. Int. J. Heat Fluid Fl 2009; 30: 768-777. 


\section{LIST OF TABLES}

Table 1. Physical and chemical properties of Repsol CEC RF-06-99 fuel.

Table 2. Real hole nozzle geometry characterization by silicone methodology. 


\section{FIGURE CAPTIONS}

Figure 1. Sample image from silicon methodology for the piezoelectric system’s nozzle

Figure 2. Spray momentum set-up

Figure 3. Injection rate for both injectors. $\mathrm{P}_{\text {inj }}=30 \mathrm{MPa}, \mathrm{P}_{\text {back }}=5 \mathrm{MPa}$

Figure 4. Injection rate for both injectors. $\mathrm{P}_{\text {inj }}=200 \mathrm{MPa}, \mathrm{P}_{\text {back }}=5 \mathrm{MPa}$

Figure 5. Spray Momentum for both injectors. $\mathrm{P}_{\text {inj }}=80 \mathrm{MPa}, \mathrm{P}_{\text {back }}=5 \mathrm{MPa}$

Figure 6 Injection rate for both nozzles for chamber pressure of $5 \mathrm{MPa}$

Figure 7 Injection rate for both nozzles for an injection pressure of $160 \mathrm{MPa}$

Figure 8. Discharge coefficient for the two injectors at different pressure conditions

Figure 9. Momentum flux signals for a chamber pressure of $50 \mathrm{MPa}$

Figure 10. Effective velocity

Figure 11. Effective diameter

Figure 12: Velocity coefficient

Figure 13. Spray outlet velocity for $\mathrm{P}_{\text {inj }}=30 \mathrm{MPa}$ and $\mathrm{P}_{\text {back }}=5 \mathrm{MPa}$

Figure 14. Spray outlet velocity for $\mathrm{P}_{\text {inj }}=200 \mathrm{MPa}$ and $\mathrm{P}_{\text {back }}=5 \mathrm{MPa}$ 


\section{TABLES}

Table 1. Physical and chemical properties of Repsol CEC RF-06-99 fuel.

\begin{tabular}{|c|c|c|c|}
\hline Test & Unit & Result & Uncertainty \\
\hline Density at $15^{\circ} \mathrm{C}$ & $\mathrm{kg} / \mathrm{m}^{3}$ & 843 & \pm 0.2 \\
\hline Viscosity at $40^{\circ} \mathrm{C}$ & $\mathrm{mm}^{2} / \mathrm{s}$ & 2.847 & \pm 0.42 \\
\hline \multicolumn{4}{|l|}{ Volatility } \\
\hline $65 \%$ distillated at & ${ }^{\circ} \mathrm{C}$ & 294.5 & \pm 3.7 \\
\hline $85 \%$ distillated at & ${ }^{\circ} \mathrm{C}$ & 329.2 & \pm 3.7 \\
\hline 95\% distillated at & ${ }^{\circ} \mathrm{C}$ & 357.0 & \pm 3.7 \\
\hline
\end{tabular}


Table 2. Real hole nozzle geometry characterization by silicone methodology.

\begin{tabular}{|c|c|c|c|c|c|}
\hline $\begin{array}{c}\text { Injection } \\
\text { system nozzle }\end{array}$ & $\mathbf{D}_{\mathbf{i}}[\boldsymbol{\mu m}]$ & $\mathbf{D}_{\mathbf{0}}[\boldsymbol{\mu m}]$ & $\mathbf{k}$-factor & $\mathbf{R}_{\mathbf{a}}[\boldsymbol{\mu m}]$ & $\mathbf{R}_{\mathbf{b}}[\boldsymbol{\mu m}]$ \\
\hline Solenoid & $133 \pm 1$ & $125 \pm 1$ & $0.8 \pm 0.2$ & $36 \pm 5$ & $25 \pm 4$ \\
\hline Piezoelectric & $132 \pm 1$ & $120 \pm 1$ & $1.2 \pm 0.2$ & $29 \pm 3$ & $19 \pm 3$ \\
\hline
\end{tabular}

